\title{
Creep testing of carbon containing refractories under reducing conditions
}

\author{
Martin Stückelschweiger ${ }^{1}$, Dietmar Gruber ${ }^{2}$, Shengli Jin ${ }^{2}$, Harald Harmuth ${ }^{2}$ \\ ${ }^{1}$ K1-MET GmbH, Linz \\ ${ }^{2}$ Chair of Ceramics, Montanuniversität Leoben, Leoben
}

\begin{abstract}
Mechanical testing of carbon containing refractories at high temperatures requires measures to protect the sample from oxidation. Therefore, special setups for tensile and compressive creep testing were developed, which prevent the oxidation of carbon in the sample. A MgO-C refractory was selected for a case study. The developments allow the quantification of the tensile and compressive creep behaviour of $\mathrm{MgO}-\mathrm{C}$ refractories at temperatures up to $1500^{\circ} \mathrm{C}$. Creep parameters are determined by an inverse evaluation method for the obtained experimental data. They enable i.g. the consideration of creep in the thermomechanical finite element simulation of refractory linings in service.
\end{abstract}

Keywords: Compressive creep; tensile creep, reducing condition, carbon containing refractories.

Journal: Journal of the International Measurement Confederation

\section{Introduction}

In service refractories are exposed to mechanical loads caused by restricted thermal expansion and temperature gradients [1]. These loads may cause irreversible deformation such as creep. Creep is defined as time- and temperature dependent deformation under constant load [2-4]. The creep strain rate $\dot{\varepsilon}$ is calculated from the derivative of strain $\varepsilon$ with respect to time, t:

$$
\dot{\varepsilon}=\frac{\partial \varepsilon}{\partial t}=\frac{\partial}{\partial t}\left(\frac{\Delta l}{l}\right)
$$

where $\Delta /$ is the change of length due to creep and $l$ is the original measurement length. The creep rate decreases initially with time (primary creep, its second derivative is negative), and then remains constant for a prolonged period (secondary creep, its second derivative is zero) and finally increases (tertiary creep, its second derivative is positive) before sample rupture.

Two standardised measures can be applied to evaluate the creep of refractories, i.e. refractoriness under load (RUL) and creep in compression (CIC) [5,6]. In the RUL method, the sample is subjected to a constant load of $0.2 \mathrm{MPa}$. During the test, the temperature increases with $5 \mathrm{~K} / \mathrm{min}$. The deformation is measured from the differential displacement of two corundum tubes through linear variable differential transducers (LVDTs). The sample shape is cylindrical with a diameter and height of $50 \mathrm{~mm}$. For $\mathrm{CIC}$ the temperature is constant after reaching the defined testing temperature. These two methods are standardised for compressive creep measurements. One drawback is that the creep starts during the heating up period and is superimposed with the thermal expansion. Hence, the beginning of creep cannot be exactly defined. Furthermore, the stress level in the test is much lower than those in typical application cases $[7,8]$. 
To counteract the above mentioned problems, two new creep testing devices were developed recently $[9,10]$. One is dedicated to compressive creep measurement at elevated loads and the other to tensile creep measurement. Both allow for tests to reach the third creep stage with proper loading conditions in a reasonable time. Furthermore, an evaluation procedure to identify the creep law parameters by an inverse procedure was developed [9]. Both devices are equipped with furnaces open to the ambient atmosphere, and are suitable to characterize the creep behaviour of refractory materials that are insensitive to oxidizing atmosphere.

A further improvement shall be done to promote the further application of the developed compressive and tensile creep devices on carbon containing materials, as the carbon will oxidize in air at elevated temperatures [11-13]. To apply a vacuum and purge with inert gas (i.g. argon) is difficult because of the openings in the furnace. In this case, the oxygen partial pressure in the area of the sample would be too high and this would lead to oxidation of the carbon. Another measure, which is frequently applied for testing of carbon containing refractories, is the embedding of the samples in coke breeze to achieve reducing conditions close to the sample surface. This is promising from a thermochemical point of view, but complicates the displacement measurement. Given the complex testing configurations of tensile and compressive creep devices, the present paper deals with the development of specific setups for creep measurements of carbon containing materials. A resin bonded MgO-C refractory was used for a case study.

\section{Material and sample preparation}

The tested material is an unburned resin bonded magnesia carbon material applied in the steel ladle. The material is annealed at the end of the production process at pyrolysis temperature of the resin for several hours. This is in contrast to burnt refractories exhibiting ceramic bonding. Fused magnesia, sintered large crystal magnesia and graphite are the raw materials. The chemical analysis of the oxides is given in Table 1. The residual carbon content after cooking under reducing conditions is $10 \%$. The composition shows a $\mathrm{CaO} / \mathrm{SiO}_{2}(\mathrm{C} / \mathrm{S})$ ratio of 3.8. This ratio is a key factor in the characterization of refractories. Depending on this ratio a series of crystalline secondary components with different refractoriness forms in service [14].

Table 1: Oxide analysis after ignition

\begin{tabular}{cccccc}
\hline Oxide & $\mathrm{MgO}$ & $\mathrm{Al}_{2} \mathrm{O}_{3}$ & $\mathrm{Fe}_{2} \mathrm{O}_{3}$ & $\mathrm{CaO}$ & $\mathrm{SiO}_{2}$ \\
\hline wt \% & 96.9 & 0.2 & 0.3 & 1.9 & 0.5 \\
\hline
\end{tabular}

To reduce the volatiles caused by the vaporisation of parts of the resin during creep testing, bricks are heat treated at $1000^{\circ} \mathrm{C}$ for 5 hours in a coke bed.

\section{Setup design}

\subsection{Compressive creep}

The compressive creep test is performed on cylindrical samples with a diameter of $35 \mathrm{~mm}$ and a height of $70 \mathrm{~mm}$. The sample is heated within $5-10 \mathrm{~K} / \mathrm{min}$ to the testing temperature. After reaching the testing temperature a dwell time of one hour follows for temperature homogenization. During heating up, a preload of $100 \mathrm{~N}$ is applied to fix the sample. Afterwards, the load application starts at a rate of $0.3 \mathrm{~mm} / \mathrm{min}$ to the defined load. The testing time, i.e. the time from load application to fracture of the sample, depends on the creep resistance of materials, the testing temperature and the applied load. 
Usually, higher loads will decrease the required testing time before creep rupture, whilst a higher temperature does not always result in shorter testing time before creep rupture. For instance, caused by the formation of mullite at high temperature, an alumina castable shows higher creep resistance at $1400{ }^{\circ} \mathrm{C}$ than $1300{ }^{\circ} \mathrm{C}$ [15]. The displacement measurement starts simultaneously with the loading procedure, and the displacement is measured directly on the sample cylindrical surface with two extensometers on the front and rear sites of the furnace. Each extensometer uses two corundum rods with an initial leg distance of $50 \mathrm{~mm}$ in the loading direction. The resolution of the extensometer is < $0.1 \mu \mathrm{m}$. The total strain is calculated from the relative displacement of the two extensometers rods and the initial measurement length. A mean displacement from the front and rear extensometer is applied for the evaluation. The end of the test is reached with sample fracture. This event is identified on a sharp load drop and automatically detected by the electronic control unit [9].

In order to perform compressive creep experiments on carbon containing materials, a setup was developed which enables to minimize the oxidation of the carbon resources contained in the sample. The setup is shown in the figure 1.

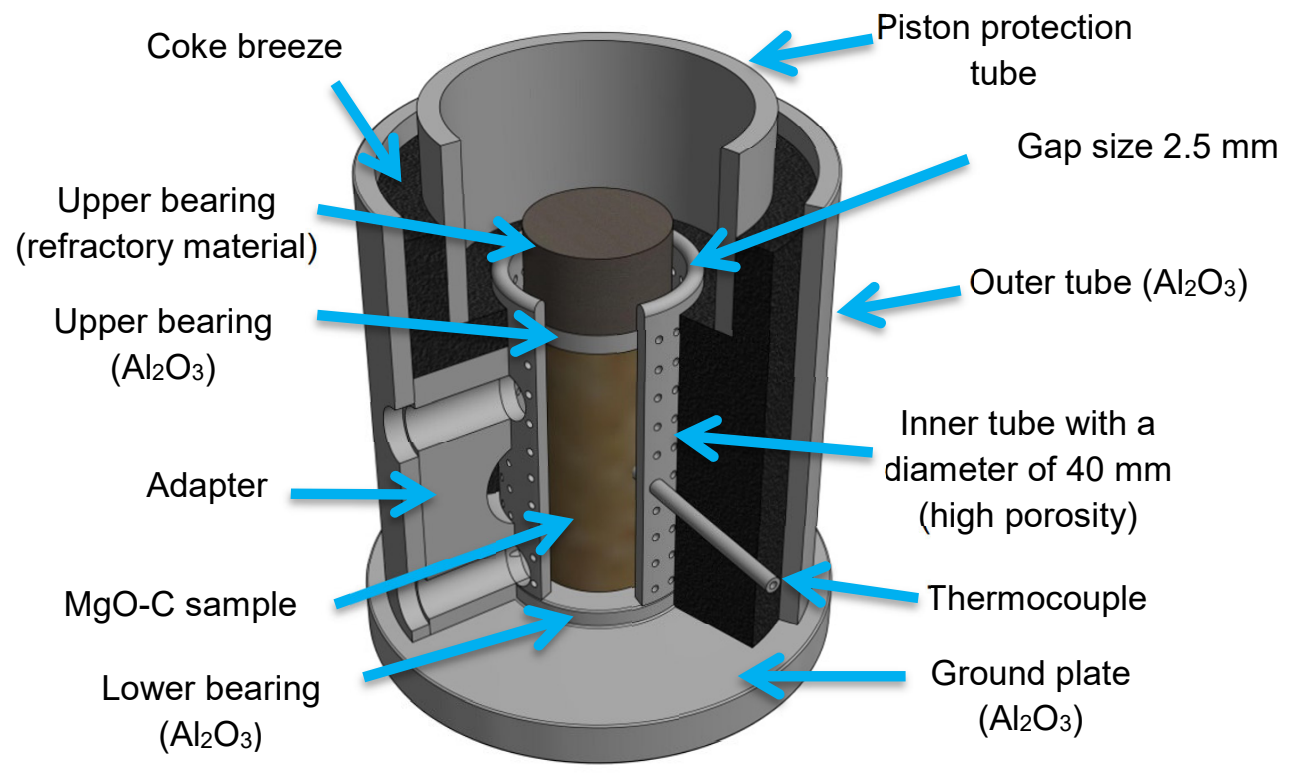

Figure 1: Setup for compressive creep in reducing conditions

The gap between the outer and inner tube is filled with coke breeze. The function of the inner tube is to separate the coke breeze from the sample. The tube has a high porosity to allow for gas diffusion. To measure the displacement on the sample during creep testing, each tube has four drilled holes for inserting the extensometer rods. Between the two tubes are adapters to protect the extensometer rods from contacting with the coke breeze. With this configuration, the setup does not influence the measurement, because the lateral surface of the sample is not in contact with the setup. The gap between sample and inner tube is $2.5 \mathrm{~mm}$.

Caused by the insulation effects of the tubes and coke breeze the actual sample temperature may differ from the measured furnace temperature. Out of this reason, the surface temperature of the sample is measured additionally by means of a thermocouple (Type $S$ ) in each test. The thermocouple is positioned at the position of half of the sample height and has an accuracy of $1^{\circ} \mathrm{C}+0.003^{*}\left(\mathrm{~T}-1100^{\circ} \mathrm{C}\right)$. The results shows that a temperature difference between the sample surface and furnace temperature is $29-31 \mathrm{~K}$ for compressive creep experiments from $1300{ }^{\circ} \mathrm{C}-1500{ }^{\circ} \mathrm{C}$. 
The test starts with the measurement of dimension and weight of the sample. The setup for the compressive creep test is assembled and the gap between inner and outer tube is filled with coke breeze. Thereafter, the whole assembly is placed in the furnace. Heating program and load application are the same as for the standard compressive creep testing procedure explained earlier. Creep tests under constant load last at maximum for 5 hours and is then stopped manually if the sample is not fractured before. During the duration of 5 hours the coke breeze offers a sufficient oxidation protection. An extension of duration might be possible if a sufficient amount of coke breeze is available. Finally, after cooling with $5 \mathrm{~K} / \mathrm{min}$, the specimen is removed from the setup, weighted and visually inspected to quantify possible oxidation.

\subsection{Tensile creep}

The tensile creep test of refractory materials is performed on cylindrical samples with a diameter of $30 \mathrm{~mm}$ and a length of $230 \mathrm{~mm}$. The maximum testing temperature is $1600^{\circ} \mathrm{C}$. The testing device allows a maximum load of $20 \mathrm{kN}$ [10]. In this test arrangement, only the middle part of the sample $(100 \mathrm{~mm})$ is surrounded by the furnace. The ends of the specimen are glued to water cooled adapters made of stainless steel. The heating procedure is similar to the compressive creep testing with a heating rate of $5 \mathrm{~K} / \mathrm{min}$ and a dwell time of one hour for temperature homogenisation in the sample. After the dwell time, the load application and the displacement measurement start simultaneously. The completion of a creep test is reached when a sharp decrease of the load occurs. Since the original test arrangement is designed only for oxidizing atmosphere, also here a setup was developed to perform tensile creep tests of carbon containing materials in reducing conditions. Again, coke breeze provides reducing conditions, the setup is shown in figure 2 .

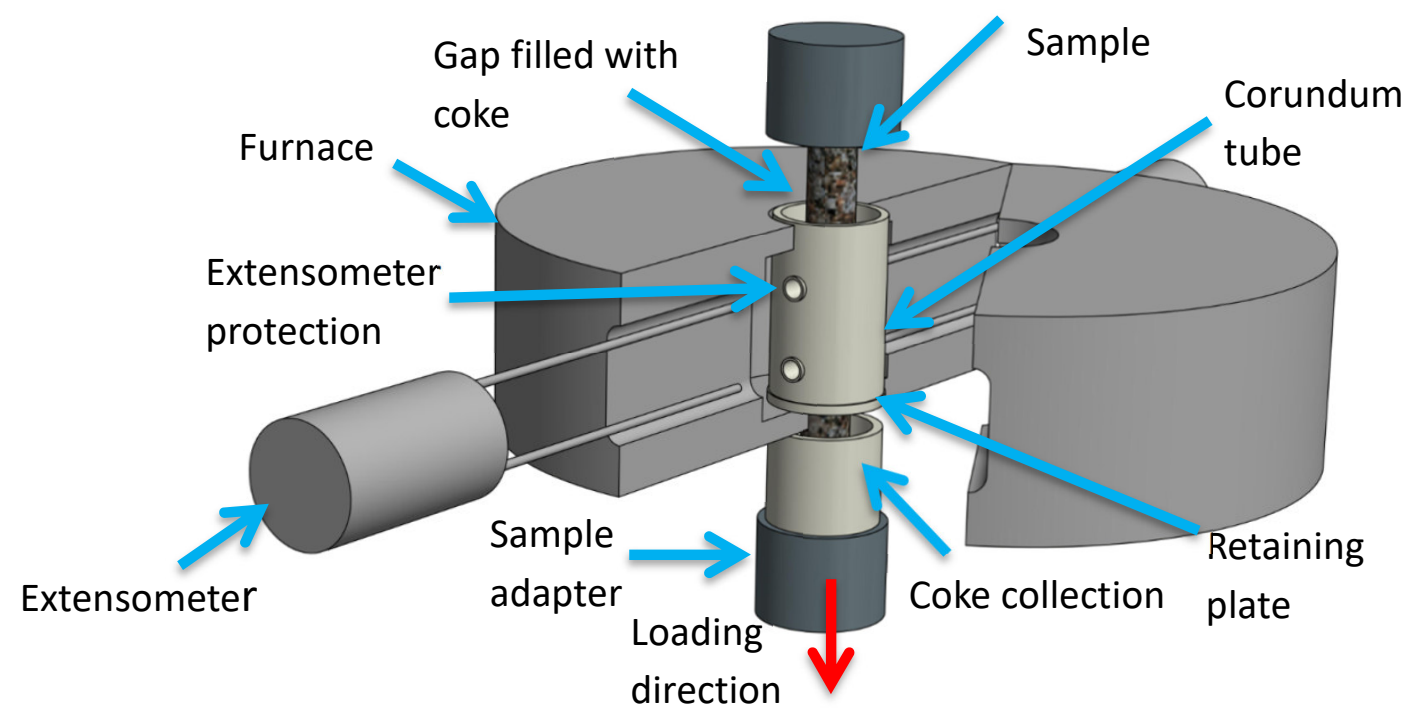

Figure 2: Setup for tensile creep testing in reducing conditions (open furnace)

Fig. 2 shows the whole test arrangement. Compared to the compressive creep test setup, the construction requires a hole in the lower retaining plate. This hole has a diameter of $35 \mathrm{~mm}$ and allows for the coke breeze to pass the gap between sample and retaining plate. So it is possible for the coke breeze to cover the lower part of the sample outside the furnace. To collect the coke breeze, an additional corundum tube was installed at the bottom of the sample. Similar to the compressive creep test, a temperature difference between the sample surface and furnace is expected and shall be measured. 
In order to apply the load during the tensile creep testing, the ends of the samples are glued to water cooled steel adapters. The maximum allowable temperature for the hardened glue is $180^{\circ} \mathrm{C}$. The glue is a two-component epoxy adhesive from the company Loctite (EA 4992). Due to the relatively high thermal conductivity of the carbon bonded refractories, this maximum temperature was exceeded for the standard sample length of $230 \mathrm{~mm}$ and the glue lost its function. Furthermore, first trials showed that the sample often fractures during load application. Out of this reason, a finite element simulations were performed to find a sample geometry ensuring temperature at the sample ends lower than 180 ${ }^{\circ} \mathrm{C}$ and lower temperature gradients in the sample to reduce the thermomechanical stresses. In the linear elastic axisymmetric model considering the cylindrical sample geometry the stresses due to the temperature gradient are simulated.

Results show that the highest stress occurs in the zone between the furnace and the water cooled adapters (Fig.3). A suitable sample length was determined in order to reduce the stresses caused by the temperature gradient to a minimum level with the maximum available sample size. Under the mentioned boundary conditions, a sample length of $310 \mathrm{~mm}$ was chosen.
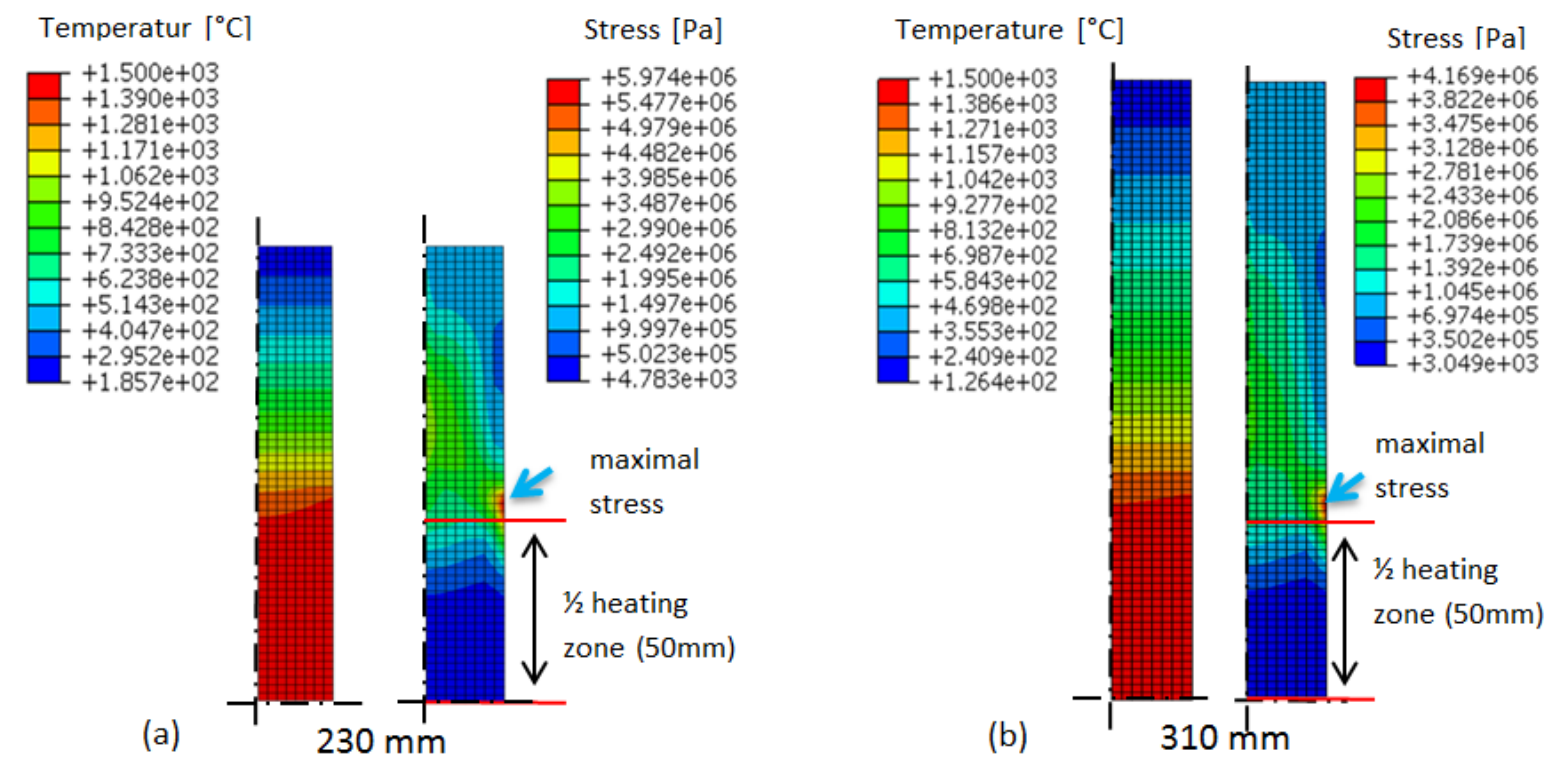

Figure 3: Simulation results for specimens with the standard (a) and modified (b) geometry

Table 2: Boundary conditions, sample dimensions and simulation results

\begin{tabular}{ccc}
\hline Geometry & Standard (a) & Modified (b) \\
\hline Furnace temperature & $1500^{\circ} \mathrm{C}$ & $1500^{\circ} \mathrm{C}$ \\
Sample length & $230 \mathrm{~mm}$ & $310 \mathrm{~mm}$ \\
Heating up period & $300 \mathrm{~min}$ & $300 \mathrm{~min}$ \\
Dwell time & $60 \mathrm{~min}$ & $60 \mathrm{~min}$ \\
Maximum stress & $5.97 \mathrm{MPa}$ & $4.17 \mathrm{MPa}$ \\
Cold end temperature & $186^{\circ} \mathrm{C}$ & $126^{\circ} \mathrm{C}$ \\
\hline
\end{tabular}

Fig. 3.a) shows the temperature und stress distributions in the standard geometry at the end of the dwell time. The results for the simulation with the modified geometry can be seen in Fig. 3.b). An increase of the sample length from $230 \mathrm{~mm}$ to $310 \mathrm{~mm}$ reduces the maximum stress by $30 \%$. Furthermore, the temperature on the cold end could be decreased from $185^{\circ} \mathrm{C}$ to $126^{\circ} \mathrm{C}$. 
The testing procedure starts with the assembling of the setup and placement in the furnace. The heating program and load application is similar to the standard tensile creep testing procedure. The maximum sample temperature is depending on the material conductivity and $1470^{\circ} \mathrm{C}$ for the tested one, with the installed electric power of the furnace.

The end of the experiment is again determined by the load drop. Afterwards the furnace is cooled to room temperature with $10 \mathrm{~K} / \mathrm{min}$. After the tensile creep test, the weight loss of the sample cannot be determined because the sample cannot be separated from the steel adapters without destruction. The samples are optically examined after each experiment.

\section{Creep evaluation procedures and Norton-Bailey creep law}

For the compressive and tensile creep evaluation presented in this paper, only the first creep stage was evaluated. The transition point between the primary creep and secondary creep stage were determined by using a polynomial fit of the mean value from the front and rear extensometer. From this curve a derivative is calculated in order to determine the transition point between the first and the second stage. As creep model for the evaluation of the experiment results the Norton-Bailey creep law is applied. The Norton-Bailey creep representation is frequently utilized in the field of refractory ceramics $[9,16,17]$. The creep function with respect to different stages is written as follows (eq. 2 ):

$$
\frac{d \varepsilon_{c r}}{d t}=K_{j}(T) \cdot \sigma^{n j} \cdot \varepsilon^{a j}
$$

Here $t$ is the creep time and $\varepsilon_{c r}$ is the creep strain, $K(T)$ is a temperature dependent function, $n$ and $a$ are the stress and the strain exponents, respectively. The subscript $j$ denotes the creep stage and falls into integers of 1,2 and 3. The Norton-Bailey creep model has already been used successfully by the authors to describe the creep behavior of refractories for the simulation of asymmetric three stages creep $[9,10]$. In order to calculate the creep strain $\varepsilon_{c r}$, the elastic strain $(\sigma / E)$ has to be subtracted from the measured total strain $\varepsilon_{t o t}$.

$$
\varepsilon_{c r}=\varepsilon_{t o t}-\frac{\sigma}{E}
$$

where $\sigma$ is the applied stress and $E$ the dynamic Young's modulus measured with the impulse excitation method (IET) using the RFDA HTVP 1650 device from IMCE.

For the inverse determination of the Norton-Bailey creep parameters $a, n$ and $K$, an in-house developed matlab code using the Levenberg-Marquardt optimization technique is applied $[9,18]$. This evaluation is based on the sum of the minimized squared differences of measured and calculated strains. 


\subsection{Young's modulus measurement}

For evaluation of the creep parameters, the Young's modulus at each temperature is required and determined with the IET at temperatures up to $1500{ }^{\circ} \mathrm{C}$ in the inert gas atmosphere $[19,20]$. The diagram below shows the results in dependency of the temperature.

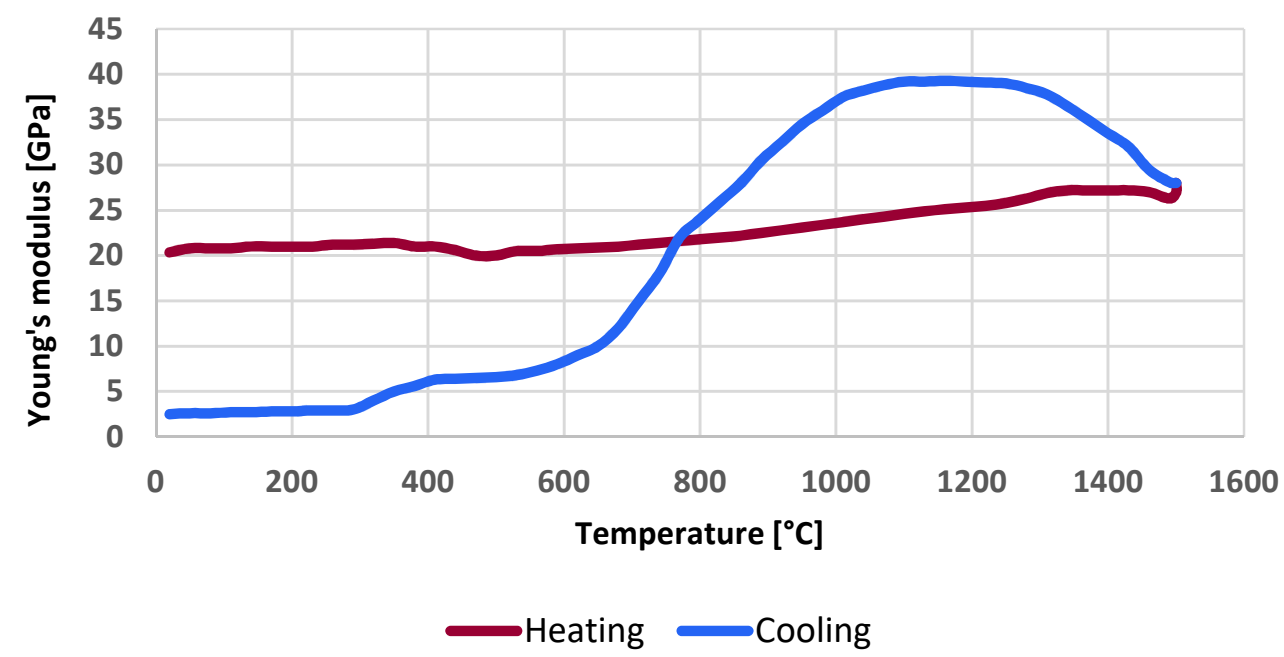

Figure 4: Young's modulus of a carbon containing material over temperature for heating and cooling

Table 3: Young's modulus at different temperatures

\begin{tabular}{cccccc}
\hline Temperature $\left[{ }^{\circ} \mathbf{C}\right]$ & $\mathbf{1 0 7 0}$ & $\mathbf{1 1 7 0}$ & $\mathbf{1 2 7 0}$ & $\mathbf{1 3 7 0}$ & $\mathbf{1 4 7 0}$ \\
\hline Heating E $[\mathrm{GPa}]$ & 24,3 & 25,2 & 26,2 & 27,2 & 27,5 \\
Cooling E $[\mathrm{GPa}]$ & 38,8 & 39,3 & 38,7 & 35,0 & $\mathbf{2 9 , 5}$ \\
\hline
\end{tabular}

It was observed that the Young's modulus increases with temperature. During the holding time of one hour a small increase of the Young's modulus is detected. In the cooling stage the Young's modulus shows a further increase with a maximum at $1100^{\circ} \mathrm{C}$. For the evaluation of creep results, values determined from the heating were applied.

\subsection{Compressive Creep of a carbon containing refractory}

In order to evaluate the Norton-Bailey creep parameters, several tests at various loading conditions are required to determine the stress and temperature dependencies. The creep measurements were carried out at $1270{ }^{\circ} \mathrm{C}-1470{ }^{\circ} \mathrm{C}$ under loads from 5 to $11 \mathrm{MPa}$. All tests were performed in reducing condition with the developed setup. The blue lines in the figures 5 to 7 represent the measurement results from the extensometer readings and the smooth red lines are the fit curves showing the primary stage of the Norton-Bailey model. 


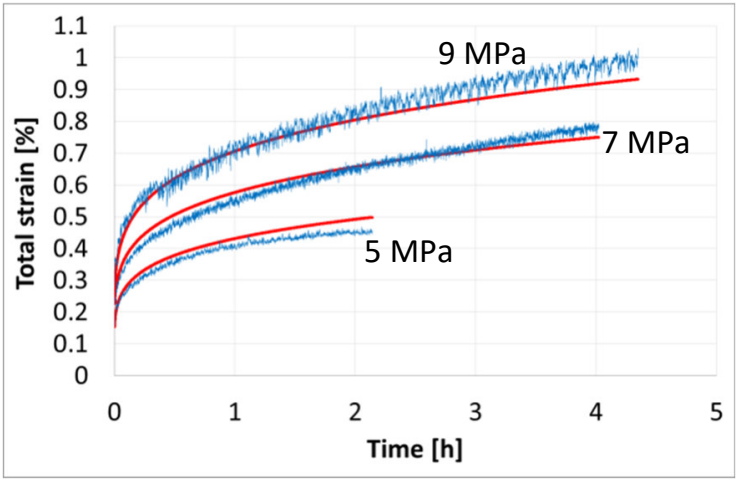

Figure 5: Creep curves of the carbon containing refractory at $1470{ }^{\circ} \mathrm{C}$

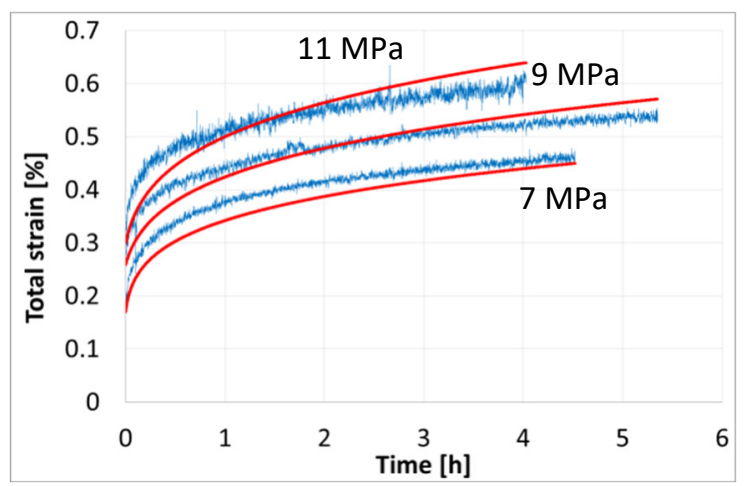

Figure 7: Creep curves of the carbon containing refractory at $1270^{\circ} \mathrm{C}$

As expected, the creep strain rises with temperature and stress. To quantify the oxidation of the carbon during the experiment, the weight loss of the sample was measured at each sample. The results are shown in the table below.

Table 4: Weight loss for tests at the given temperatures

\begin{tabular}{cc}
\hline Temperature $\left[{ }^{\circ} \mathrm{C}\right]$ & Average weight loss [\%] \\
\hline 1470 & 1,3 \\
1370 & 1,1 \\
1270 & 1,0 \\
\hline
\end{tabular}

This weight loss increases with temperature. However, it is very likely that the indirect oxidation also contribute to the total weight loss, besides the direct oxidation of carbon [21]. Figure 8 shows a sample before and after creep experiment.

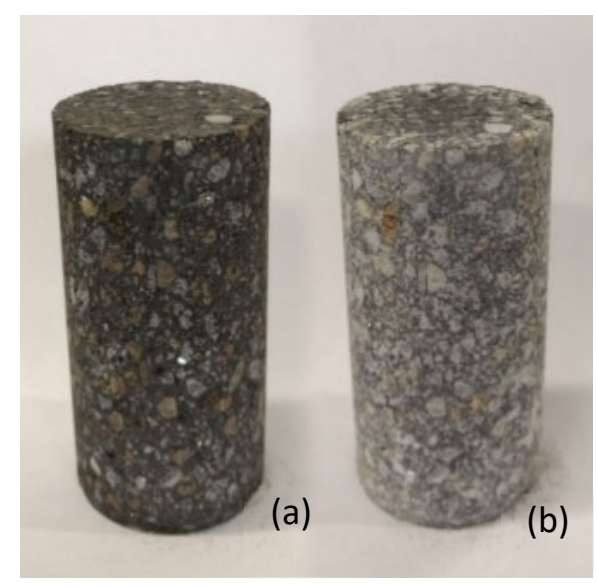

Figure 8: Sample (a) before creep test and (b) after creep test at $1470^{\circ} \mathrm{C}$ 
In order to receive the Norton-Bailey creep parameters nine creep curves were evaluated. The corresponding Norton-Bailey creep parameters are listed in Table 5. Results show the increase of the temperature dependent coefficient $K$ with increasing temperature. In the evaluation, the parameters $a$ and $n$ were fit with constant values over all three temperatures. Since this method achieved a good fit, the material indicates no major change in the creep mechanism in the tested temperature region. A separate evaluation for each temperature would not change the fit significantly. The difference between parameter $n$ and $a$ is relatively small and $a$ is negative ( $n=4.058$ and $a=-4,064)$.

Table 5: Norton-Bailey creep parameters for primary compressive creep

\begin{tabular}{|c|c|c|c|}
\hline Temperature & $K\left[\mathrm{MPa}^{-\mathrm{n}} \mathrm{s}^{-1}\right]$ & $n$ & $a$ \\
\hline $1270^{\circ} \mathrm{C}$ & $4.2 \mathrm{E}-21$ & $\Gamma$ & r \\
\hline $1370^{\circ} \mathrm{C}$ & $5.3 \mathrm{E}-21$ & 4.1 & -4.1 \\
\hline $1470^{\circ} \mathrm{C}$ & $8.3 E-21$ & & \\
\hline
\end{tabular}

\subsection{Tensile creep of a carbon containing refractories}

Tensile creep tests were performed in a temperature range between $1130^{\circ} \mathrm{C}$ and $1430^{\circ} \mathrm{C}$. The applied loads (1.4 MPa, 1.6 MPa and 1.8 MPa) were relatively small to obtain distinct creep curves. The diagrams (Fig. 9- Fig. 11) below show the creep curves with different loads at the respective temperatures.

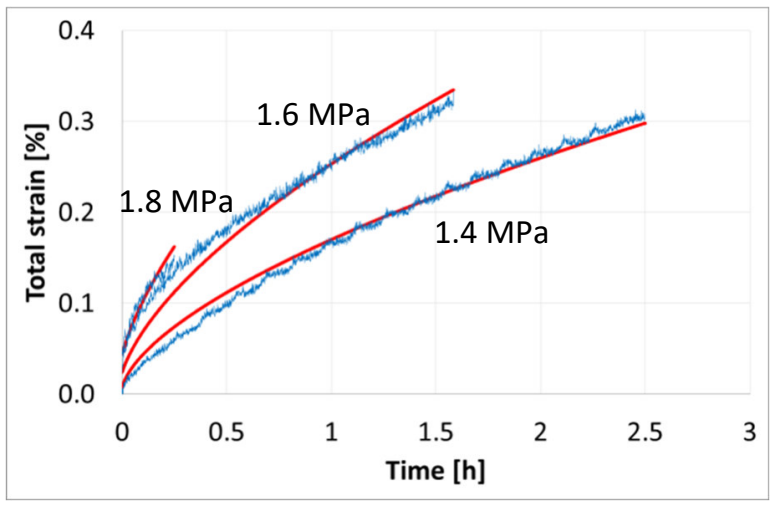

Figure 9: Creep curves of the carbon containing refractory at $1430^{\circ} \mathrm{C}$

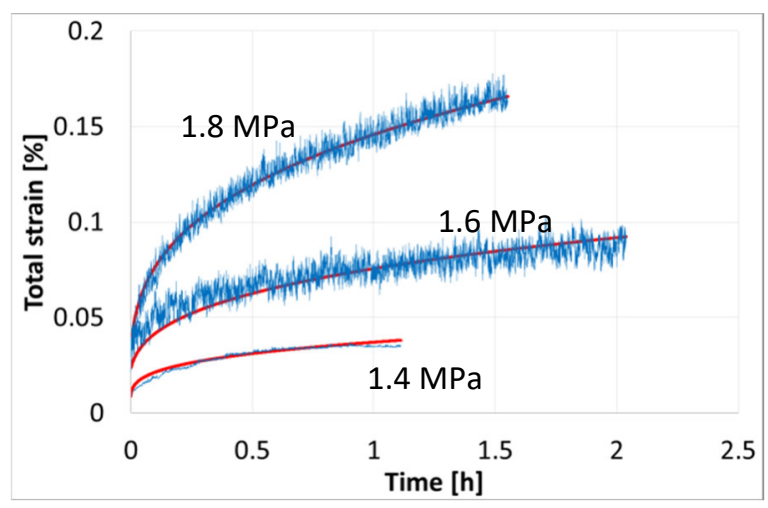

Figure 11: Creep curves of the carbon containing refractory at $1130^{\circ} \mathrm{C}$

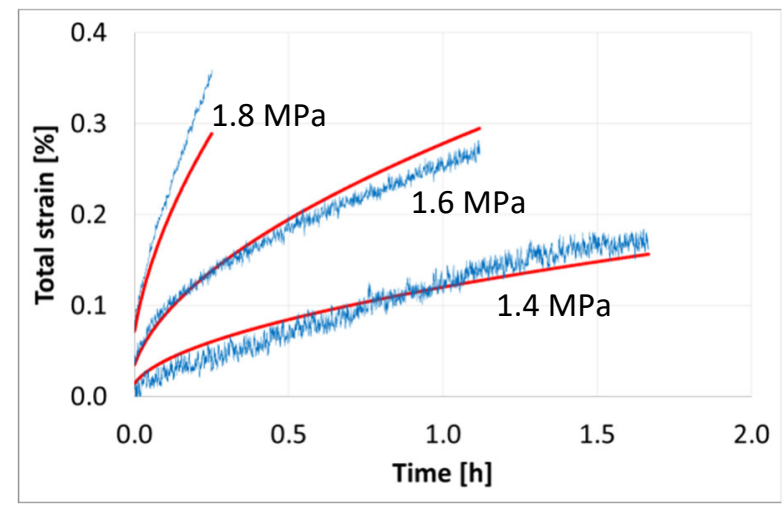

Figure 10: Creep curves of the carbon containing refractory at $1340^{\circ} \mathrm{C}$

The diagrams show increasing creep deformation with increasing temperature and stress. The evaluation procedure of the Norton-Bailey creep parameters for tensile creep and the first creep stage 
works in the same way as for the compressive creep tests, although the parameters $n$ and $a$ are temperature dependent in this case (Tab.6).

Table 6: Norton-Bailey creep parameters for primary tensile creep

\begin{tabular}{cccc}
\hline Temperature & $K\left[\mathrm{MPa}^{-\mathrm{n}} \mathbf{s}^{-1}\right]$ & $\boldsymbol{n}$ & $\boldsymbol{a}$ \\
\hline $1130^{\circ} \mathrm{C}$ & $1.3 \mathrm{E}-19$ & 20.1 & -2.4 \\
$1340^{\circ} \mathrm{C}$ & $1.1 \mathrm{E}-13$ & 15.6 & -1.3 \\
$1430^{\circ} \mathrm{C}$ & $5.8 \mathrm{E}-10$ & 4.1 & -0.8
\end{tabular}

The temperature depending function $K$ and the strain component $a$ show an increase with respect to temperature, and the stress component $n$ shows a decrease with increasing temperature. Figure 12 below shows a tensile creep sample after high temperature test. The red circle marks the area where the upper extensometers touch the specimen during the experiment for the displacement measurement. In this area, slight traces of oxidation are visible only on the surface.

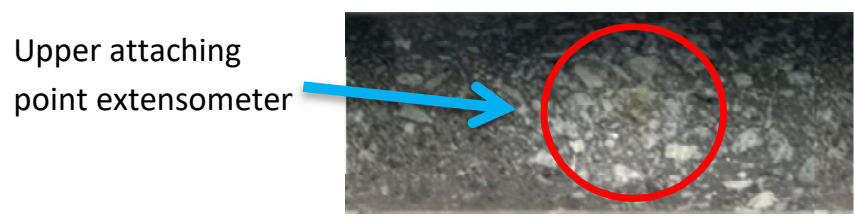

Figure 12: Tensile creep sample after high temperature creep test

\section{Summary}

New setups to perform tensile and compressive creep tests under service related loads on carbon containing refractories were introduced in this paper. These developments allow for creep measurements in reducing condition and the determination of creep parameters in the first and the second creep stage in tension and compression. The oxidation of the carbon in the material during testing at temperatures up to $1500^{\circ} \mathrm{C}$ could be reduced by the surrounding of coke breeze. Finally creep test results were presented for a resin bonded magnesia carbon material and the Norton-Bailey creep parameters for the primary creep stage were successfully evaluated. The results show also a pronounced asymmetric creep behaviour between tension and compression. For an evaluation of complete creep curves including the second and the third creep stages, a further improvement of the oxidation protection is required. This is an item for further research.

\section{References}

[1] C.A. Schacht, Refractories Handbook, Marcel Dekker Inc., New York, 2004, pp. 369-394.

[2] M. Longhin, D. Shelleman, J. Hellmann, A methodology for the accurate measurement of uniaxial compressive creep of refractory ceramics, Measurement 111 (2017) 69-83.

[3] ISO 3187, Refractory products - Determination of creep in compression. (1989)

[4] J.T. Boyle, J. Spence, Stress analysis for creep, Butterworths, England, 1983.

[5] I. Matsumura, Y. Hayashi, Y. Hiyama, A. Ijiri, Refractoriness under load and hot creep measurements, Taikabutsu Overseas 2 (2) (1990) 36-42.

[6] EN 993-9, Methods of test for dense shaped refractory products - Determination of creep in compression. (1973)

[7] D. Gruber, H. Harmuth, Thermomechanical Behaviour of Steel Ladle Linings and the Influence of Insulations, Steel Research International 85 (4) (2014) 512-518. https://doi.org/10.1002/srin.201300129.

[8] S. Jin, D. Gruber, H. Harmuth, R. Rössler, Thermomechanical failure modelling and investigation into lining optimization for a Ruhrstahl Heraeus snorkel, Engeneering Failure Analysis (62) 2016, 254-262. https://doi.org/10.1016/j.engfailanal.2016.01.014. 
[9] S. Jin, H. Harmuth, D. Gruber, Compressive creep testing of refractories at elevated loads - Device, material law and evaluation procedure, J. Euro. Ceram. Soc. 34 (15) (2014) 4037-4042. https://doi.org/10.1016/i.jeurceramsoc.2014.05.034.

[10] A. Sidi Mammar, D. Gruber, H. Harmuth, S. Jin, Tensile creep masurement of ordinary ceramic refratories at serivce related loads including setup, ceep law, testing and evaluation procedures, Ceramic International 42 (6) (2016) 67916799. https://doi.org/10.1016/j.ceramint.2016.01.056.

[11] T. Zhu, Y. Li, M. Luo, S. Sang, Q. Wang, L. Zhao, Y. Li, S. Li, Microstructure and mechanical properties of MgO-C refractories containing graphite oxide nanosheets (GONs), Ceramics International 39 (3) (2013) 3017-3025.

[12] X. Li, M. Rigaud, S. Palco, Oxidation Kinetics of Graphite Phase in Magnesia - Carbon Refractories, Journal of the American Ceramic Society 78 (4) (1995) 965-971.

[13] V.G. Rocha, R.Menéndez, R.Santamaría, C.Blanco, M.Granda, Oxidation behaviour of magnesia-carbon materials prepared with petroleum pitch as binder, Journal of Analytical and Applied Pyrolysis 88 (2) (2010) 207-212. https://doi.org/10.1016/j.jaap.2010.04.008.

[14] Deutsche Gesellschaft Feuerfest- und Schornsteinbau, Refractory Enginneering: Materials-Design-Consctruction, $2^{\text {nd }}$ revised and updated edition, Vulkan-Verlag, Essen, 2005. pp. 11.

[15] S. Jin, H. Harmuth, D. Gruber, St. Schachner, P. Meunier, R. Techer, Advanced creep testing of refractories providing new insight into material behaviour, Refractories WORLDFORUM 10 (2) (2018) 63-67.

[16] W.R. Cannon, T.G. Langdon, Creep of ceramics, Journal of Materials Science 18 (1) (1983) 1-50.

[17] E. Drouelle et.al, Deformation mechanisms during high temperature tensile creep of Ti3AIC2 MAX phase, Journal of Alloys and Compounds 693 (2017) 622-630.

[18] D.W. Marquardt, An algorithm for least-squares estimation of nonlinear parameters, SIAM Journal of Appl. Math 11 (2) (1968) 431-441. http://dx.doi.org/10.1137/0111030.

[19] J. Wernera, J. Fruhstorfer, A. Mertke, C. Odea, C. G. Aneziris, The influence of nano scaled additions on the Young's modulus of carbon-bonded alumina at temperatures up to $1450^{\circ} \mathrm{C}$, Ceramics International 42 (14) (2016) 15718-15724. https://doi.org/10.1016/j.ceramint.2016.07.031.

[20] T.M. Souza, A.P.M. Mati , M.A.M. Brito, V.C. Pandolfelli, Oxidation protection system for hot elastic modulus evaluation of refractory ceramics, Ceramics International 40 (5) (2014) 7595-7600. https://doi.org/10.1016/j.ceramint.2013.11.118.

[21] A.S. Gokce, C.Gurcan, S. Ozgen, S. Aydin, The effect of antioxidants on the oxidation behaviour of magnesia-carbon refractory bricks, Ceramics International 34 (2) (2008) 323-330. https://doi.org/10.1016/j.ceramint.2006.10.004. 